\title{
Editorial
}

\section{¿Investigar por investigar?}

Desde el comienzo de los tiempos, la humanidad ha sentido curiosidad por los fenómenos, en principio naturales, que suceden a su alrededor. Esa búsqueda insaciable de respuestas a aquellas cosas que no se comprenden y posteriormente la solución a las amenazas que los circundan han hecho que a lo largo de los años se creen y establezcan pautas para que de forma sistemática se estructure el conocimiento mediante la observación, el razonamiento y la realización de pruebas y ensayos organizados de forma metódica.

Aproximadamente, hacia el año 500.000 A.C. se estima que el Homo erectus logró producir fuego de forma controlada, con el propósito de cocer alimentos, generar calor y alejar a posibles depredadores que atentaran contra su vida. Esto se pudo conseguir gracias a la observación de los fenómenos naturales que lo generaban y al posterior conjunto de pruebas y ensayos que permitieron, a través de la fricción de elementos como rocas y piedras, reproducir el fuego a voluntad.

La ciencia moderna tiene sus orígenes en las grandes civilizaciones de la Antigüedad como la sumeria, la babilónica, la mesopotámica, la egipcia, la china, la griega, entre otras, siendo esta última una de las que más documentos científicos produjo de forma escrita. Un común denominador de estas civilizaciones es que la producción de conocimiento se daba de forma empírica y, en muchos casos, justificada sobre la idea de una deidad, pero siempre sobre la base de la necesidad de explicar los fenómenos naturales circundantes y de ofrecer soluciones a las necesidades en un principio básicas y después orientadas al bienestar.

Las civilizaciones precolombinas, como la azteca, la maya y la inca, no eran ajenas a esta manifestación inherente al ser humano de sentir curiosidad e intentar entender y explicar lo que sucede a su alrededor. Realizaron grandes avances en agricultura, astronomía, arquitectura, etc. y vieron su caída con la llegada de los españoles, los cuales impusieron sus costumbres, religión, estructura social y, en consecuencia, la forma de investigar sustentada, al igual que las civilizaciones de antaño, en la creencia en un dios.

Pese al oscurantismo que reinó en Occidente durante la Edad Media, el conocimiento científico siempre encontró caminos y formas de abrirse paso. Por ello, en el declive de la Edad Media nacen las primeras universidades como 
centros de reunión entre profesores y académicos en torno al aprendizaje, lo que sirvió de antesala al Renacimiento, iniciado en Italia en el siglo XIV. Uno de sus principales exponentes, Galileo Galilei, apoyó sus investigaciones sobre la base del método científico, lo que lo ubica como el padre de las ciencias modernas.

De Galileo hasta el día de hoy, la concepción de investigación y sus procesos adjuntos se han ajustado a los retos cada vez más cambiantes de la sociedad, pero sustentados sobre la idea de antaño: la curiosidad constante, el querer dar una explicación racional a aquellos fenómenos desconocidos, siguiendo un proceso sistemático y metódico.

Sin embargo, una mirada crítica al desarrollo actual de la investigación a nivel mundial genera varios interrogantes. Hoy por hoy, la investigación se desarrolla en grandes centros de I+D financiados por asociaciones público-privadas, que en definitiva quieren resolver problemas puntuales que en su mayoría generen dividendos y, por qué no, mejoren las condiciones de vida de los seres humanos, aunque esto último no sea siempre el objetivo. Por otra parte, se encuentra la investigación al interior de las universidades, en institutos que congregan grupos de investigación que a priori son más autónomos en las temáticas que investigan, aunque sujetos a un presupuesto limitado, si este proviene de los propios recursos de la universidad.

En Colombia, así como en otras partes del mundo, desde principios del presente siglo, para conseguir mejores resultados de investigación desde las universidades, los gobiernos formularon leyes y normas, con el fin de obtener dichos resultados por decreto y plasmarlos en indicadores de producción científica, lo que llevó a exigir al profesor a aumentar el número de publicaciones, con el ánimo de mantener su contrato o aumentar el salario. Ese tipo de acciones, en principio no está mal, es bueno que se reconozca el trabajo, pero de "calidad". Sin embargo, el afán de generar productos sobre investigaciones inocuas y vacías y que no aportan en nada, es cada vez más frecuente. El nacimiento de revistas predadoras en las cuales se paga para que se publique cualquier cosa, sin importar la calidad, está en aumento; al parecer la frase "publicar o perecer", que viene acuñándose desde hace unos años, toma cada vez más fuerza. Se ha desvirtuado el concepto de investigación, que por siglos se había venido construyendo, para dar paso a una mecanización del proceso y una valoración en términos de indicadores superfluos; es por eso por lo que es necesario hacer un alto en el camino y preguntarse, ¿investigar por investigar?

\section{César Leonardo Trujillo Rodríguez, PhD. cltrujillo@udistrital.edu.co Universidad Distrital Francisco José de Caldas}

